\title{
Field Test and Numerical Simulation on Bearing Capacity of Squeezed Branch Pile in Transmission Line
}

\author{
Wang DEHONG*, Ju YANZHONG**, Zhao XIAOPAN***, Bai JUNFENG**** \\ *Northeast Dianli University, Jilin 132012 China, E-mail: hitwdh@126.com \\ **Northeast Dianli University, Jilin 132012 China, E-mail: juyanzhong@126.com \\ ***Northeast Dianli University, Jilin 132012 China, E-mail: 158264590@qq.com \\ ****Northeast Dianli University, Jilin 132012 China, E-mail: baijunfeng521016@163.com \\ cross $^{\text {ref }}$ http://dx.doi.org/10.5755/j01.mech.23.5.19357
}

\section{Introductions}

Transmission lines rely on strong tower foundations, because the bearing performance of the foundation directly affects the operational security of transmission line. Foundation projects therefore take up a large proportion of the time and costs resulting from transmission line construction. As China's economy and society have rapidly developed, accelerated construction of power infrastructure and rising voltage levels have magnified the loads that foundations must support. In order to meet the uplift and alternating pressure requirements for larger loads, ultrahigh voltage (UHV) transmission line projects make use of pile foundations with larger length and diameter; this is especially true in areas with soft soil, where the pile diameter can reach $2.2 \mathrm{~m}$ or more, significantly increasing engineering cost, construction time, and potential environmental impacts. Therefore, it has become necessary to design a rational transmission line foundation that can reduce engineering efforts, construction costs, and potential damage to the environment.

Designed based on the bionics principle, the squeezed branch pile is a kind of variable section pile with branches or plate. The origins of this pile can be traced to India in the 1960s [1-2]; later, in the 1980's, Ogura (1987, 1988) in Japan and Martin (1983) in US investigated the bearing capacity of nodular cylinder piles through model tests [3-5]. Subsequently, there were fewer reports about the squeezed branch pile until it came into use in China in the 1990's. Since then, many researchers have studied its bearing performance and operational mechanism. Some researchers (Zhang, 2005; Gao, 2007; Kong, 2013; Wang, 2015) have used the finite element model or experiments to study the squeezed branch pile' $\mathrm{s}$ bearing capacity mechanism and other crucial factors, including diameter, quantity, spacing, and position of branches or plates [6-9]. The results indicate that the squeezed branch pile has higher bearing capacity and experiences less settlement because of the enlarged branches and plates that have been widely used in the construction of bridge projects and thermal power plants in China. However, there are few reports of using this type of pile in transmission lines. The load experienced by a transmission line foundation is different from that of bridges or other industrial and civil construction foundations, in that transmission lines are characterized by alternating uplift and pressure load. The uplift loadcarrying capacity of normal pile is usually far below the pressure load-carrying capacity, and the pile size is there- fore usually determined by the uplift load [10]. Compared with normal pile, the uplift bearing capacity of squeezed branch pile is significantly higher, which may enable it to overcome normal pile's disadvantage of low uplift bearing capacity in transmission line projects.

At present, research into squeezed branch pile mainly focuses on bearing performance under uniaxial loads; however, transmission line foundations bear both horizontal and vertical alternating loads. The ratio of horizontal and vertical loads for a corner tower can reach as high as 1:4, levels at which the influence of horizontal loads on the bearing performance of the pile cannot be ignored [11]. It is important to understand the behavior of squeezed branch pile under both vertical and horizontal loads, as this may provide theoretical and technical support for applying these piles in transmission line projects.

This paper discusses the bearing performance of squeezed branch pile as studied through field static load tests and a finite element model; elements of bearing performance assessed include the development of skin friction, pile tip resistance variation, displacement field distribution, and plastic zone development of soil around the pile. The influence on the bearing performance of both branch quantity and the ratio of horizontal load to vertical load are also analyzed, and some design suggestions are proposed.

\section{Experiments}

Based on the details of a $1000 \mathrm{kV}$ UHV transmission line project and the load case SZ304-66 tower, two squeezed branch pile were designed and constructed. In order to analyze the action of the branch, a normal pile with the same diameter and length was designed and constructed for purposes of comparison. The normal pile was numbered \#1, and the two squeezed branch piles were numbered \#2 and \#3. The diameters of all three piles were $600 \mathrm{~mm}$, the lengths were $16.7 \mathrm{~m}$, the branch diameters were $1400 \mathrm{~mm}$, the branch heights were $700 \mathrm{~mm}$, and the center of the branch was $7000 \mathrm{~mm}$ from the design ground. The test site was in the city of Yangzhou, in Jiangsu province, which is characterized by lacustrine deposition red plain topography. According to geological data, the $30.0 \mathrm{~m}$ depth strata can be divided into a total of six layers, with the physical and mechanical properties of each soil layer shown in Table 1.

Experiments used the static load test method. The test system consisted of reaction steel beam, anchor piles, and hydraulic jacks, with two anchor piles used to provide 
counter-force. The settlement of the test pile was measured by displacement sensors attached to an independent frame, and the data was read and recorded by a computer. The loading history of the pile tip was determined based on Chinese code GB 5007-2011 [12]. The test processing was controlled by the settlement of the pile top, and the load test was terminated once an inflexion point appeared on the load-settlement $(Q-s)$ curve, or once the pile settlement exceeded $80 \mathrm{~mm}$ when the $Q-s$ curve of the pile head varied gradually.

Table 1

Physical-mechanical parameters of soil strata

\begin{tabular}{|c|c|c|c|c|}
\hline $\begin{array}{c}\text { Soil } \\
\text { layer } \\
\text { No. }\end{array}$ & $\begin{array}{c}\text { Geotechnical } \\
\text { name }\end{array}$ & Depth, m & $\begin{array}{c}\text { Cohe- } \\
\text { sion, } \\
\mathrm{kPa}\end{array}$ & $\begin{array}{c}\text { Internal } \\
\text { friction } \\
\text { angle, }\end{array}$ \\
\hline I & $\begin{array}{c}\text { Cultivated } \\
\text { soil }\end{array}$ & 1.1 & 5.0 & 0 \\
\hline II & $\begin{array}{c}\text { Silty clay } \\
\text { with silt }\end{array}$ & 6.6 & 20.1 & 6.0 \\
\hline III & $\begin{array}{c}\text { Silty clay } \\
\text { and silt in- } \\
\text { terbedded }\end{array}$ & 13.4 & 13.5 & 8.0 \\
\hline IV & $\begin{array}{c}\text { Silty clay } \\
\text { with powder }\end{array}$ & 19.5 & 20.0 & 8.8 \\
\hline V & Silt clip & 27.2 & 9.0 & 20.2 \\
\hline VI & Silty clay & 30.0 & 21.7 & 12.4 \\
\hline
\end{tabular}

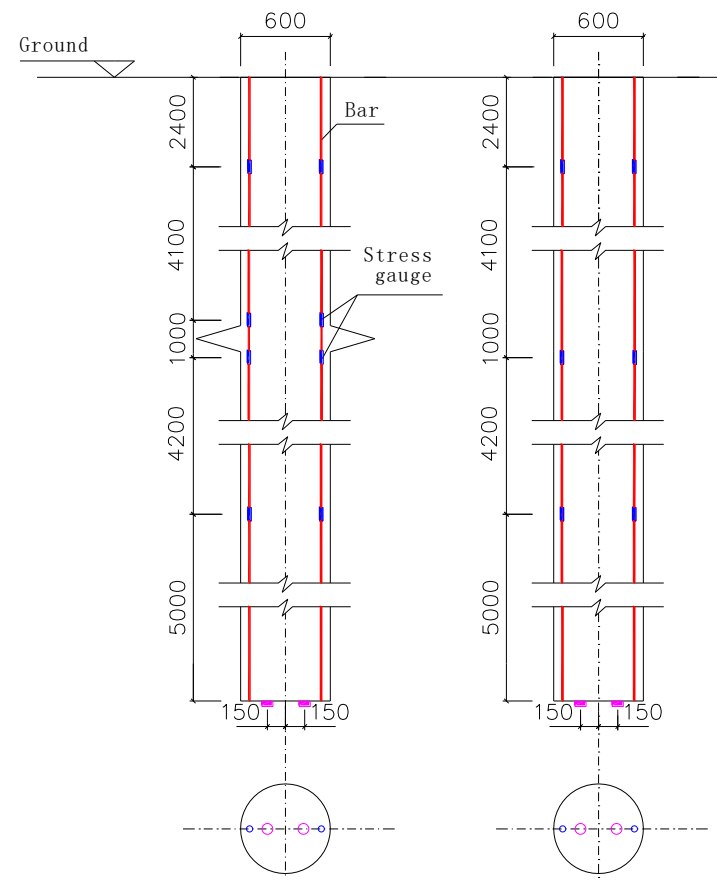

Fig. 1 The arrangement of string wire stress gauges and soil pressure cells

In order to study the axial load transfer mechanism, string wire stress gauges were attached to reinforcing bars at different depths, with two gauges symmetrically arranged in each section. Eight steel stress gauges were used in each squeezed branch pile at depths of 2.4, 6.5, 7.5, and $11.7 \mathrm{~m}$, while six steel stress gauges were used in the normal pile at depths of $2.4,7.5$, and $11.7 \mathrm{~m}$. The piles ended in a symmetric arrangement of two soil pressure cells for measuring tip resistance, as shown in Fig. 1. The string wire stress gauges and soil pressure cells were connected to acquisition instruments by cables.

\section{Experimental results and analysis}

\subsection{Load versus settlement relationship}

Fig. 2 shows the $Q$-s curve of the test piles, where $Q$ represents the vertical load and s represents settlement. In general, the data show that the settlement values of both the normal pile and the branch piles increase slowly when the applied load is less than $1000 \mathrm{kN}$, making the $Q-s$ curve approximately linear. The settlement levels gradually increase with the loads. When the load on pile \#1 reaches $1735 \mathrm{kN}$, the settlement increases significantly. As Figure 3 shows, the settlement value under the $1735 \mathrm{kN}$ load is $24.43 \mathrm{~mm}$, while the total settlement value is $36.99 \mathrm{~mm}$. For test piles \#2 and \#3, inflexion points appear on the $Q-s$ curves when the loads reach $2007 \mathrm{kN}$ and $2053 \mathrm{kN}$, respectively; according to Chinese code GB 5007-2011 [12], take the load value as ultimate bearing capacity of the pile, the load value corresponds to the inflexion point. The ultimate bearing capacities of piles \#1, \#2, and \#3 were $1550 \mathrm{kN}$, $1780 \mathrm{kN}$, and $1825 \mathrm{kN}$, respectively, meaning that the bearing capacity of the branch pile was $16.3 \%$ higher than that of the equal diameter normal pile under the same conditions. This can be attributed to the existence of the branch, which provides larger resistance; however, the side resistance is reduced because the effective pile length of contact with soil declines.



Fig. $2 Q$-s curves for static loading tests

The failure process of a branch pile differs from that of a normal pile with equal diameter. The rate of settlement increase for a branch pile is slow, and it remains slow when approaching ultimate bearing capacity. Overall, the settlement is far less than that of a normal pile with the same diameter, which can be attributed to the branch resistance; therefore, the failure process shows a typical ductile feature, which is very advantageous for the security of a transmission line's tower.

\subsection{Axial force of piles}

Fig. 3 shows the axial force distribution curves for piles \#1, \#2, and \#3 under each level of loading. The data were calculated according to the string wire stress gauge readings at each level, using the equation $N i=(E s A s+E c$ Ac) $\varepsilon i$, where $N i$ represents the axial load of section I; Es 
represents the elastic modulus of the reinforcing bars, $E s=200000 \mathrm{~N} / \mathrm{mm}^{2}$; $E c$ represents the elastic modulus of concrete, $E s=32500 \mathrm{~N} / \mathrm{mm}^{2}$; As represents the cross sectional area of the reinforcing bars; $A c$ represents the cross sectional area of the concrete; and $\varepsilon i$ represents the strain of cross section $i, \varepsilon i=(\varepsilon i 1+\varepsilon i 2) / 2$. As Fig. 5 shows, the axial force of the test piles gradually decreases as the average depth increases. The greater the load of the pile top, the greater the difference between the pile tip axial force and the pile top load. The axial force of the squeezed branch pile takes a sharp change at the branch location, reducing significantly below the branch; this sudden change increases with the pile top load. This occurs because the side resistance works earlier than the branch resistance, and the load percentage shared by the branch resistance increases with the pile top load, such that the axial force of the pile above the branch is significantly greater than that of the pile below the branch.

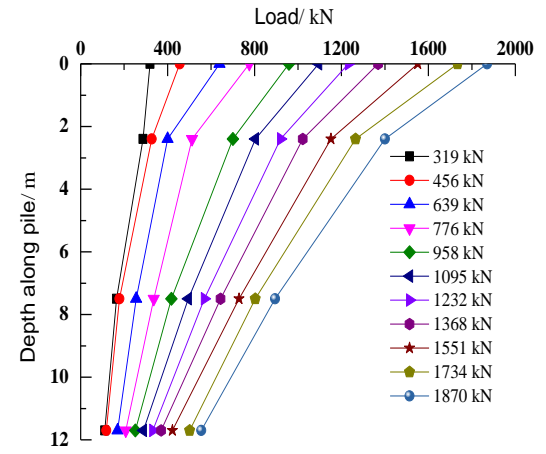

a

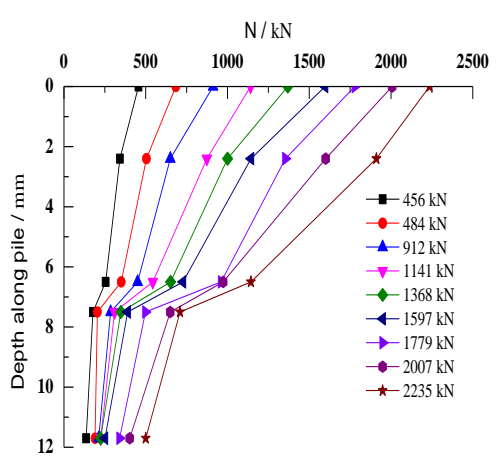

$\mathrm{b}$

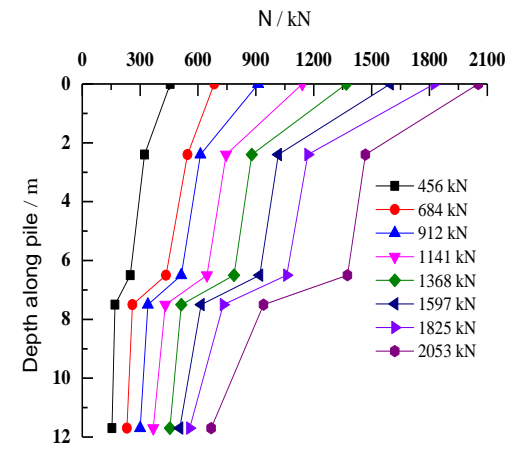

c

Fig. 3 Axial forces of test a) \#1 test pile, b) \#2 test pile and c) \#3 test pile

\subsection{Side friction resistance}

Fig. 4 plots the side friction resistance against the load for the squeezed branch piles. When the squeezed branch pile is subject to vertical loads, displacement occurs between the soil and the pile, such that the pile's side friction begins to take effect. As the friction resistance curve shows, during the early loading period the load is shared among the side friction resistance, branch resistance, and tip resistance, and the side friction resistance of the upper pile increases as the load increases. When the load increases past a certain value, the lower part of the branch pile's side friction resistance gradually comes into play; however, because the branch pile side resistance bears a larger load, friction on the lower portion of the branch pile grows more slowly.

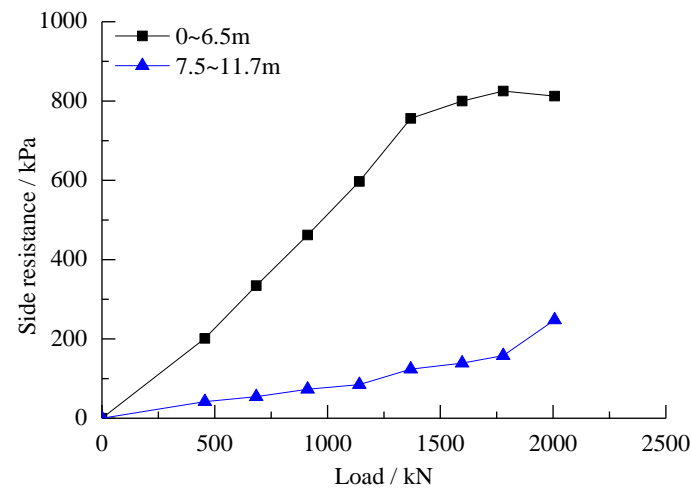

a

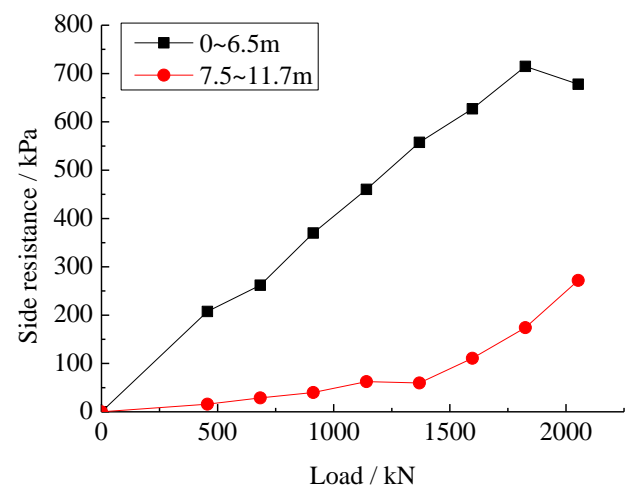

b

Fig. 4 Side friction distribution of squeezed branch a) \#2 test pile side friction and b) \#3 test pile side friction

\subsection{Bearing capacity of branch and tip resistance}

The load shared by the branch can be computed based on the difference in axial force between the upper and lower interface of the branch. The results show that as the vertical load increases, the loads that the branches undertake gradually increase; at the limit of its capacity, the load on the branch of pile \#2 is $390 \mathrm{kN}$ and the load on the branch of pile \#3 is $462 \mathrm{kN}$, accounting for $22 \%$ and $25 \%$, respectively, of the ultimate bearing capacity.

The data for tip resistance were recorded based on to the readings of the soil pressure cells at each level. Re- sistance is calculated as $P k=\sigma k A p$, where $P k$ represents the tip resistance of load level $k ; A p$ represents the cross sectional area of the pile; and $\sigma k$ represents the stress of the soil under the pile tip for load level $k, \sigma k=(\sigma \mathrm{k} 1+\sigma k 2) / 2$. Fig. 5 shows the pile tip resistance under different load levels. The data show that the initial tip resistance accounts for a smaller proportion than side friction resistance, indicating that the tip resistance plays a lagging role. As the load increases, the tip resistance begins to increase; when the load reaches its maximum, the tip resistance of test piles \#1, \#2, and \#3 are $125 \mathrm{kN}, 70 \mathrm{kN}$, and $82 \mathrm{kN}$, respectively, accounting for $8.1 \%, 3.9 \%$, and $4.4 \%$, respectively, 
of the piles' ultimate bearing capacity. The tip resistance of test pile \#1 is slightly larger than those of test piles \#2 and \#3; this is because the settlement of the equal diameter normal pile is greater than that of the branch pile under the same load, which allows the tip resistance to come fully into play.

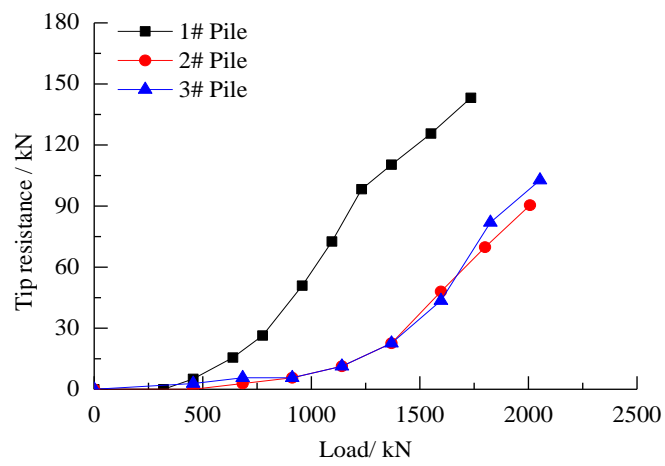

Fig. 5 Tip resistance of test piles

\section{Numerical simulations}

The finite element model of the squeezed branch pile and the surrounding soil was constructed by ABAQUS. The squeezed branch pile was assumed to be made of continuous, homogeneous elastomers, and the linear elastic constitutive model was used to describe the pile. The Coulomb molar (M-C) model was used to describe the soil, with a three-dimensional solid reduction unit C3D8R used for the model of the piles and soil. Considering the contraction of the pile-soil interface, the contact element adopted the elastoplastic Coulomb friction model, and the contact surface friction coefficient remained unchanged [7]. In order to eliminate the effects of soil boundaries, the soil take was set at 40 times the radius of the pile diameter, with the depth take set at the pile length, and the stress balance of the soil was calculated before loading.

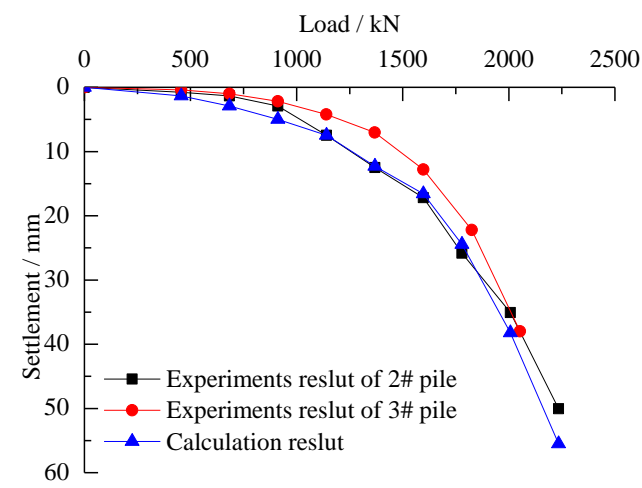

Fig. 6 Comparison of finite element and experimental load displacement curves

Test piles \#2 and \#3 can serve as examples to verify the rationality of the modeling methods and the validity of the finite element model. Fig. 6 compares the loadsettlement curves of the numerical and experimental results. The data show that the overall trend of the loadsettlement curves remains relatively similar during the entire loading process, although the finite element settlement is slightly larger than the experiment results. Taking into account the actual difference between the ideal numerical calculation and the geological conditions of the site, the modeling method appears to be reasonable and feasible.

\subsection{Displacement of soil around pile}

Fig. 7 shows the horizontal displacement of soil around the pile at different depths under $2053 \mathrm{kN}$ loading, based on radial distances from the center of the pile of $0.7 \mathrm{~m}, 1.3 \mathrm{~m}, 2.5 \mathrm{~m}, 4.4 \mathrm{~m}$, and $8.6 \mathrm{~m}$. The data in Fig. 11 show that as the radial distance away from the center of pile increases, the horizontal displacement of soil around the pile decreases; similarly, horizontal displacement of soil mutations occurs at the position of branch, but the mutation becomes unclear as the distance from the center of the pile increases.

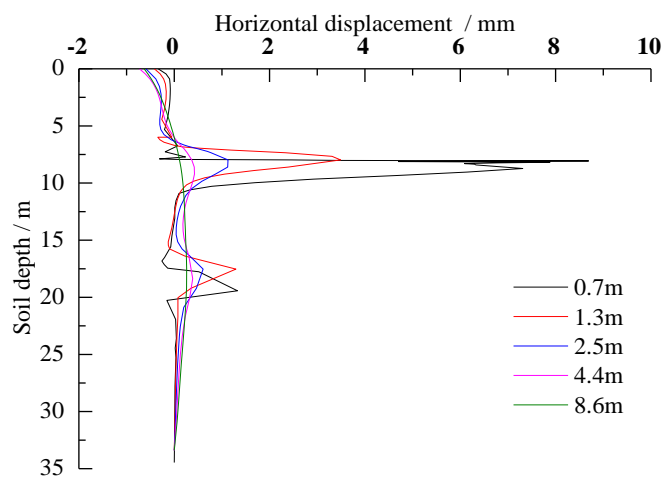

Fig. 7 Horizontal displacement of soil around pile

Fig. 8 shows the vertical displacement of soil around the pile under the maximum load value. The result show that the maximum vertical soil displacement $(54.27 \mathrm{~mm})$ occurs below the branch plate. Meanwhile, the vertical displacement of the soil at the pile tip (maximum displacement of $48.52 \mathrm{~mm}$ ) is relatively large, mainly due to the significant squeezing action of the branch and pile tip, and the soil above the branch separate with the branch's upper surface.

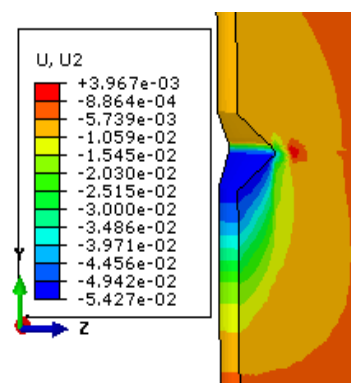

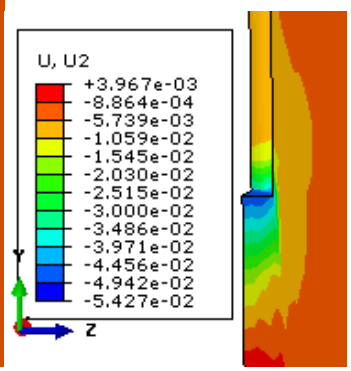

Fig. 8 Vertical displacement of soil around pile a) Position of branch and b) Position of pile tip

\subsection{Vertical stress of soil around pile}

Fig. 9 shows the vertical stress of the soil $0.3 \mathrm{~m}$, $0.7 \mathrm{~m}, 1.08 \mathrm{~m}, 1.74 \mathrm{~m}$, and $2.23 \mathrm{~m}$ away from the pile center, when the working load on the pile top is $2053 \mathrm{kN}$. The vertical stress of the soil around the pile increases with the 
soil depth. At a distance of $0.3 \mathrm{~m}$ from the pile, the range of variation in vertical stress is large, especially above and below the branch $(6.5-7.5 \mathrm{~m})$ and near the pile tip; the change in vertical soil stress decreases as the radial distance away from the pile center increases. The vertical stress tends to remain stable beyond about $1.74 \mathrm{~m}$ away from the pile center, which indicates that the influence of the distance on soil stress can be ignored when the distance exceeds 1.3D, where $\mathrm{D}$ represents the branch diameter. Considering the principle of additional stress superposition, it is recommended that the minimum center distance between piles in a group should not be less than 1.5D.

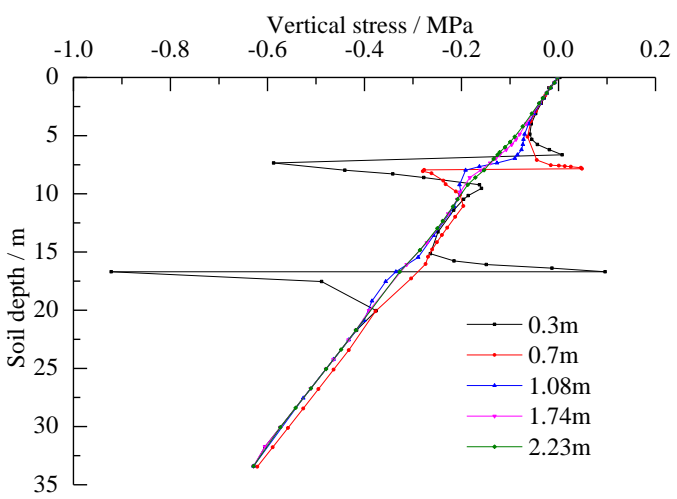

Fig. 9 Vertical stress of soil around pile

\subsection{Relative displacement between pile and soil}

Fig. 10 shows the relative displacement between the pile and the soil under different loads. These data indicate that the relative displacement between the pile and the soil is divided into two parts separated by the branch. As the load increases, the growth rate of the relative displacement between the pile and the soil becomes larger, and a mutation occurs below the branch and pile tip. This maybe explained by the fact that the soil below the branch and pile tip is consistently compressed, and the pressure deformation of the soil equals the displacement of the branch and pile tip such that the relative displacement between the pile and the soil decreases rapidly.

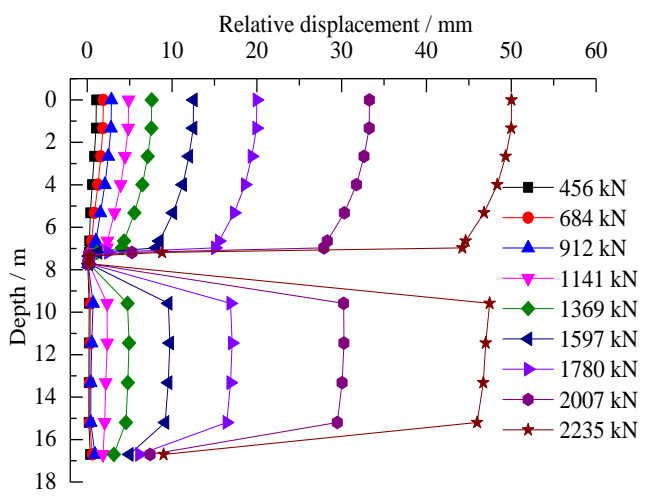

Fig. 10 Relative displacement between pile and soil

\subsection{Plastic development of soil around pile}

Fig. 11 depicts the plastic zone distribution of soil around the pile at different loading stages. The data indicate that the plastic zone arises first at the position of the branch when the load is $1140 \mathrm{kN}$; as the load increases, the plastic zone also begins to appear in the pile tip, and a plastic area gradually develops along both the branch and pile tip. This occurs because the soil below the branch and pile tip deforms under compression loading, and while most of the deformation comes from the consolidation of soil, some arises from compaction action. When the load increases to a certain value, the soil at the pile tip loses its bearing capacity, and the load that the squeezed branch pile can bear reaches its maximum.

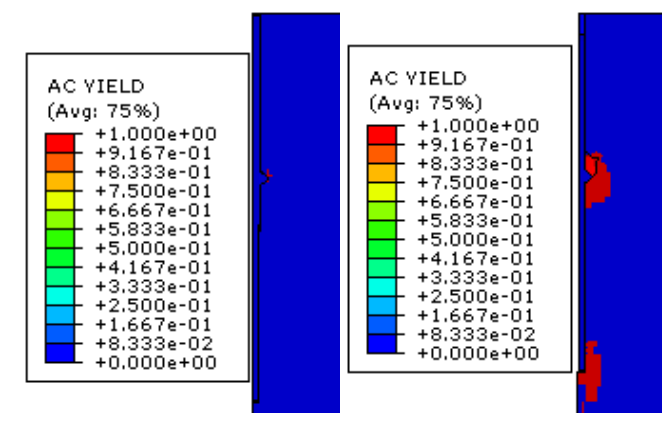

a

b

Fig. 11 Plastic zone distribution of soil around pile: a) $Q=1140 \mathrm{kN}$ and b $Q=2235 \mathrm{kN}$

4.5. The influence of branches on the vertical bearing capacity of piles

In order to investigate the influence of branch quantity on the bearing capacity of squeezed branch piles, the bearing capacity of piles with 1,2, and 3 branches were calculated on the basis of tests. Considering the effect on bearing capacity, the spacing of branches should be greater than 1.5 times the branch diameter and 3 times the pile diameter; in other words, $3.0 \mathrm{~m}$ is the appropriate spacing for branches in this situation [9].

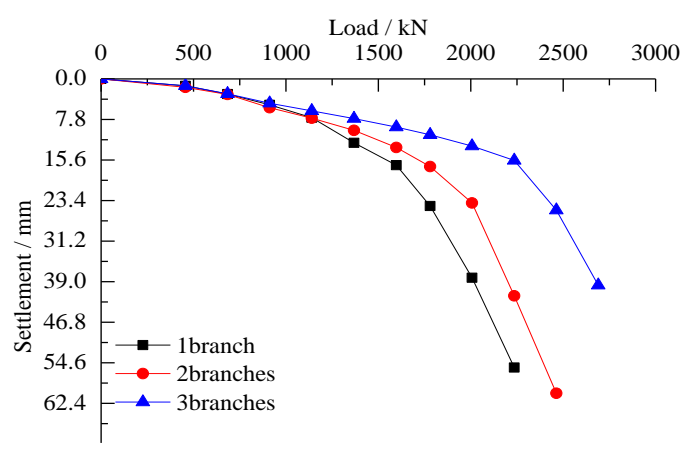

Fig. $12 Q-s$ curve of squeezed branch piles with different branch quantities

Fig. 12 shows the load-settlement curves of squeezed branch piles with different numbers of branches. The data indicate that the bearing capacity of the piles increases as the branch quantity increases; the bearing capacities of squeezed branch piles with 1, 2, and 3 branches are 1780, 2007, and $2235 \mathrm{kN}$, respectively. The bearing capacity of the squeezed branch piles increases about $12.8 \%$ when the branch quantity increases by 1 . Therefore, within a certain range, the bearing capacity of squeezed branch 
piles can be greatly improved by increasing the number of branches; however, considering geological engineering conditions and pile length, too many branches can produce unfavorable results, such that the optimum branch quantity for this situation is 1 to 3 .

\subsection{Influence of horizontal load on vertical displacement of pile}

Analysis was also conducted to investigate the influence of the horizontal load on the bearing capacity of squeezed branch piles. Considering the ratio between horizontal loads and vertical loads in actual projects, the settlement of squeezed branch piles was calculated under six load conditions, include uniaxial vertical loading and five kinds of vertical loads with different horizontal loads. The squeezed branch piles had two branches spaced at $3.0 \mathrm{~m}$, with the other parameters identical to those of the test piles.

Fig. 13 plots settlement under these different load conditions. The data indicate that when the load is smaller, the influence of the horizontal load on the vertical pile settlement is not obvious; however, as the load increases, the effects of the horizontal load on vertical pile displacement become more obvious. Under the same vertical load, the amount of settlement decreases as the horizontal load increases, because friction resistance in the squeezed branch pile improves through the action of horizontal loading.

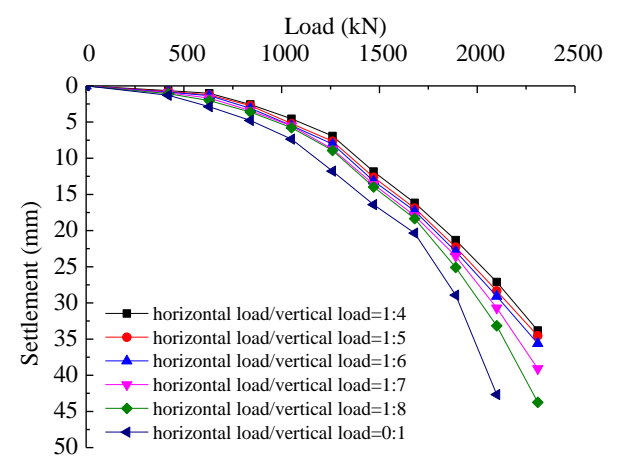

Fig. $13 Q$-s curve squeezed branch piles under different load conditions

\section{Conclusions}

This study analyzed the mechanical performance and bearing capacity of squeezed branch piles through field static load tests and the finite element analysis method. The main results are as follows:

1. Under the same conditions, the ultimate bearing capacity of squeezed branch piles increases by 16 to $30 \%$ compared with normal piles of the same diameter. Within a certain range, increased branch quantities lead to increases in ultimate bearing capacity and decreases in vertical pile displacement. In terms of engineering design, it is advisable to identify the optimal branch quantity for the particular bearing stratum; under the terms articulated in this paper, the optimum number of branches was 1 to 3 .

2. The axial force of the squeezed branch pile is characterized by an obvious step change at the position of the branch under vertical loading, and friction resistance works in sequence.
3. In the context of transmission line foundations, horizontal loading can improve the frictional resistance of the pile, exerting a significant restrictive effect on the vertical displacement of squeezed branch pile.

4. Variations in vertical soil stress depend largely on the position of the branch and pile tip, with variation decreasing as the radial distance away from the pile center increases. It is recommended that the minimum center distance between piles in a group should not be less than $1.5 \mathrm{D}$.

5. The relative displacement between the pile and the soil increases gradually as the pile tip load increases, with a mutation occurring below the branch and pile tip. The plastic zone of the soil is found primarily in regions adjacent to the pile below the branch and pile tip.

\section{References}

1. Subhash, C.; Khepar, S. D. 1964. Double underreamed piles for foundations in black cotton soils. Indian Concrete Journal 2: 50-52.

2. Jain, G. S.; Gupta, S. P. 1972. Deformation of soil around a multi-under-reamed pile. Indian Concrete Journal 6: 239-241. http://worldcat.org/issn/00194565.

3. Martin, R. E.; De Stephen, R. A. 1983. Large diameter double underreamed drilled shafts. Journal of Geotechnical Engineering 109(8): 1082-1098. http://dx.doi.org/10.1061/(ASCE)07339410(1983)109: 8(1082).

4. Ogura, H.; Yamagata, K.; Kishida, H. 1987. Study on bearing capacity of nodular cylinder pile by scaled model test. J. Struct. Constr. Eng. 87-97.

5. Ogura, H.; Yamagata, K.; \& Ohsugi, F. 1988. Study on bearing capacity of nodular cylinder pile by fullscale test of jacked piles. J Struct Eng. 386: 66-77.

6. Zhang, H.; Qian, D. L. 2005. Reliability analysis of vertical bearing capacity of single squeezed branch pile. Rock Mechanics and Engineering 24(22): 41974201(in Chinese). http://dx.doi.org/1000-6915(2005)22-4197-05.

7. Gao, X. J.; Wang, J. C.; Zhu, X. R. 2007. Static load test and load transfer mechanism study of squeezed branch and plate pile in collapsible loess foundation. Journal of Zhejiang Univ. Sci. A. 8(7): 1110-1117. http://dx.doi.org/10.1631/jzus.2007.A1110.

8. Kong, L. G.; Jiang, L. H.; Chen, R. P.; et al. 2013. Response of squeezed branch piles under inclined uplift loads. Chinese Journal of Applied Mechanics 30(2): 228-233 (in Chinese). http://dx.doi.org/10.11776/cjam.30.02.B040.

9. Wang, Y. L.; Xu, L. Y.; Li, B. Q. 2015. Finite element numerical study on the axial bearing behaviors and actors of squeezed branch pile. China Civil Engineering Journal 48(S2): 158-162 (in Chinese). http://dx.doi.org/1000-131X(2015)S2-0158-05.

10. Lu, X. L.; Cheng, Y. F. 2005. Current Status and Prospect of Transmission Tower Foundation Engineering in China. Electric Power Construction, 26 (11): 25-27, 34 (in Chinese). http://dx.doi.org/1000-7229(2005)11-0025-03.

11. Xiao, Q.; Wang, D. H.; Xu, J. 2013. Research on characteristics of squeezed branch piles in transmission line engineering. Water Resources and Power 31(10): 
189-191, 238 (in Chinese).

http://dx.doi.org/1000-7709(2013)10-0189-04.

12. Code for design of building foundation. GB 5007-2011(in Chinese).

Wang Dehong, Ju Yanzhong, Zhao Xiaopan,

Bai Junfeng

\section{FIELD TEST AND NUMERICAL SIMULATION ON BEARING CAPACITY OF SQUEEZED BRANCH PILE IN TRANSMISSION LINE}

\section{S u m m a r y}

By applying static load tests and the finite element analysis method, this study assesses the load-bearing performance and load transfer mechanism of squeezed branch piles. This study also compiles data and discusses findings about the distribution of field displacement, the development of a plastic zone in the soil, and the influence of branch quantity and horizontal load on the vertical bearing capacity. The results show that the axial force of the squeezed branch pile changes obviously at the site of the squeezed branch. Additionally, this study identifies the sequenced effects of frictional resistance; the displacement patterns of the soil around the pile, particularly below the branch and pile tip; the minimum center distance between piles in a group, which should be greater than 1.5 times the branch diameter; and the location of plastic strain in the soil below the branches and pile tip. The data reveal that the vertical bearing capacity of squeezed branch pile is 16 to $30 \%$ higher than that of normal pile under the same conditions; furthermore, the vertical bearing capacity of squeezed branch pile increases as the number of branches and horizontal load increase. Considering geological engineering conditions and loading requirements, it is advisable to identify an optimum branch quantity for the specific bearing stratum; in this case, the optimum branch quantity was 1 to 3 .

Keywords: transmission line foundation; squeezed branch pile; bearing capacity; horizontal load; field test.

Received September 14, 2016 Accepted October 13, 2017 